\title{
The Roles of Gibberellins and Ethylene on the Germination Physiology of the Malting Barley, Variety Puma (Hordeum valgare cv Puma)
}

\author{
P. ZANAMWE* \\ Department of Botany and Biotechnology, University of Johannesburg, P. O. Box 524, Auckland Park, \\ Johannesburg, 2006, South Africa \\ (Received 15 June 2018; Accepted 21 March 2019; \\ Communicated by A. Goyal)
}

\begin{abstract}
The separate roles of ethylene and gibberellins on seed germination have not been clearly established. This has limited full utilisation of these hormones in barley malting. This study was carried out to investigate the roles of gibberellins and ethylene on the germination physiology of 'Puma' barley seeds. Germination curves, percent germination, rootlets length and respiration rates of seeds treated with ethylene, 1-methylcyclopropane (1-MCP), gibberellic acid $\left(\mathrm{GA}_{3}\right)$, daminozide (B-nine), $\mathrm{GA}_{3}+$ ethylene, $\mathrm{GA}_{3}+1-\mathrm{MCP}$, ethylene $+\mathrm{B}$-nine, $1-\mathrm{MCP}+\mathrm{B}$-nine and the control were compared after 24,48 and $72 \mathrm{~h}$ from soaking, respectively. $\mathrm{GA}_{3}$ and ethylene treatments were used to investigate the effects of increasing endogenous ethylene and $\mathrm{GA}_{3}$ levels, respectively. B-nine and 1-MCP treatments were used to assess the effects of inhibiting gibberellins synthesis and ethylene perception, respectively. Combination treatments were used to assess hormonal interactions. $\mathrm{GA}_{3}$ and ethylene treatments suppressed germination after $24 \mathrm{~h}$, but, had no effect after 48 and $72 \mathrm{~h}$, respectively. $\mathrm{B}$-nine, ethylene $+\mathrm{B}$-nine and 1-MCP $+\mathrm{B}$-nine suppressed germination, rootlet elongation and respiration after 24,48 and $72 \mathrm{~h}$, respectively. 1-MCP and $\mathrm{GA}_{3}+1-\mathrm{MCP}$ stimulated germination after $24 \mathrm{~h}$, but, had no effect after 48 and $72 \mathrm{~h}$, respectively. $\mathrm{GA}_{3}+$ ethylene treatment suppressed germination and rootlet elongation but stimulated respiration after 24 h. Ethylene suppressed rootlets elongation after 24, 48 and $72 \mathrm{~h}$ from soaking, respectively. GA appeared to be the dominant germination hormone, and ethylene, to regulate the rate of germination through suppression of rootlets elongation.
\end{abstract}

Keywords: 1-MCP, B-nine, percent germination, respiration rate, rootlet growth.

Abbreviations: 1-MC, 1-Methylcyclopropane; B-nine, Daminozide; GA, Gibberellin; $\mathrm{GA}_{3}$, Gibberellic acid

\section{Introduction}

Gibberellin (GA) and ethylene are prominent seed germination promotion hormones (Corbineau et al. 2014). The germination promotion effect of GA appears to be universal, but the germination promotion effect of ethylene varies with plant species (Matilla and Matilla-Vázquez 2008). In barley, both GA and ethylene are synthesised during seed

*Corresponding author; E-mail: zanamwep@gmail.com 
germination (Locke et al. 2000; Hartman et al. 2011). Since both hormones are present, it is difficult to attribute the germination stimulation effect to one hormone and not the other.

In plant species whose seed germination is promoted by ethylene, it is assumed that ethylene either stimulate GA synthesis or affects GA signal pathway, which then promotes seed germination (Corbineau et al. 2014). This is partly because GA promotes germination of many plant species whose germination is also promoted by ethylene (Kucera et al. 2005). For example, gibberellic acid $\left(\mathrm{GA}_{3}\right)$ and ethylene promotes germination of dormant seeds of Arabidopsis (Matilla and Matilla-Vázquez 2008). This was also because ethylene promotes stem elongation of submerged rice (Oryza sativa) through stimulation of GA synthesis (Taiz and Zeiger 2010). Moreover, treatment of ethylene insensitive (etrl) mutant Arabidopsis seeds with $\mathrm{GA}_{3}$ stimulates germination (Corbineau et al. 2014).

Conversely, GA was reported to promote germination in some plant species by stimulating ethylene production (Corbineau et al. 2014). For example, incubation of embryos of beechnut seeds in $\mathrm{GA}_{3}$ solution resulted in increased ethylene production (Calvo et al. 2004a; Corbineau et al. 2014). The puzzle was further complicated by the fact that ethylene and GA share common seed germination promotion mechanisms, e.g., antagonism of abscisic acid (ABA, a germination inhibiting hormone) action, promotion of biosynthesis and release of germination enzymes and promotion of cell elongation (Kucera et al. 2005; Taiz and Zeiger 2010; Miransari and Smith 2014). It is therefore clear that the separate roles of ethylene and GA in seed germination have not been clearly established.

GA is routinely used to accelerate germination and grain modification (breaking down of cell walls and enzymatic conversion of insoluble starch and proteins to soluble forms) during malting of barley (Briggs 1998). Although not currently being used in malting, ethylene was also reported to promote germination and synthesis of grain modification enzymes in barley seeds (Locke et al. 2000). Therefore, understanding the separate roles of ethylene and GA on barley seed germination may have the potential to improve the way they would be manipulated in barley malting. This study was, therefore, carried out to investigate the separate roles of GA and ethylene, as well as their possible interaction during germination of 'Puma' barley, a variety that is widely malted in South Africa. Inhibitors of hormone synthesis or action were used to separate the roles of one hormone from the other.

\section{Material and Methods}

\section{Plant material and sample preparation}

'Puma' barley grain of the 2014 winter production season was used. The grain was obtained from SAB-Alrode malting (SAB-Alrode, 2 Johnson Street, Alrode, South Africa). The experiments were carried out in September 2015 ensuring that the grain attained enough after-ripening. The grain was screened to remove kernels that were less than 2.2 $\mathrm{mm}$ so as to reduce variations in germination that could result from seed size differences. 
After screening, the grain was surface sterilised with $1 \%$ sodium hypochlorite solution and rinsed 5 times with distilled water. After sterilisation, the grain was air dried to its original moisture content $(12 \%)$.

\section{Germination test}

\section{Treatments and germination conditions}

Nine treatments were compared, viz; ethylene, $\mathrm{GA}_{3}, \mathrm{GA}_{3}+$ ethylene, daminoside (Bnine), 1-methycylopropene (1-MCP), ethylene + B-nine, $\mathrm{GA}_{3}+1-\mathrm{MCP}, 1-\mathrm{MCP}+\mathrm{B}$-nine and the control. In each treatment, six replicates of 100 seeds each were germinated on two layers of Whatman No. 1 filter papers moistened with $5 \mathrm{ml}$ distilled water (except in the B-nine containing treatments) in a $9 \mathrm{~cm}$ diameter Petri-dish. For all treatments, Petridishes were placed in hermetically sealed $60 \mathrm{~cm}^{3}$ glass tanks and the glass tanks were placed in a growth chamber (germinator) where temperature and light were controlled. Seeds were germinated at $20 \pm 1{ }^{\circ} \mathrm{C}$ under continuous darkness (except during evaluations). Out of the six replicates, three replicates were used in assessing percent germination and the remaining three replicates were used for assessment of rootlets length.

\section{Preparation of treatments}

For ethylene containing treatments (ethylene, ethylene $+\mathrm{B}$-nine, ethylene $+\mathrm{GA}_{3}$ ), six open/unclosed Petri-dishes containing 100 seeds each per treatment were placed in 60 $\mathrm{cm}^{3}$ glass tank. The glass tank was closed with a size fitting glass sheet with two $1 \mathrm{~cm}$ diameter holes on it and sealed air tight with a sole tape. A plastic pipe was connected from a $1 \mathrm{~cm}$ diameter hole on the closing glass sheet though a 51 glass jar containing ethylene gas and out of the germinator to the air pump. Air was pumped at a rate of 11.1 $\mathrm{ml} / \mathrm{h}$ though the 51 glass jar containing ethylene gas and again though the glass tank in which the Petri-dishes were placed and out though the other $1 \mathrm{~cm}$ diameter hole on the closing glass sheet; forming a flow though system. After $24 \mathrm{~h}$, commensurate to the first $24 \mathrm{~h}$ of incubation, the pump was stopped, and the glass tank was opened. The glass tank was then kept open until the end of the germination experiment period $(72 \mathrm{~h})$. However, the Petri-dishes were closed to avoid rapid moisture loss. For 1-MCP (Smartfresh ${ }^{\mathrm{TM}}$, Agro Fresh, Pennsylvania, USA) containing treatments (1-MCP, 1-MCP + B-nine and $\left.\mathrm{GA}_{3}+1-\mathrm{MCP}\right)$, six open Petri-dishes containing 100 seeds each per treatment were placed in $60 \mathrm{~cm}^{3}$ glass tank (same as for ethylene containing treatments). A $35 \mathrm{ml}$ beaker containing $0.1 \mathrm{~g} \mathrm{1-MCP}$ powder was placed in the glass tank. The tank was closed with size fitting glass sheet with a $1 \mathrm{~cm}$ diameter hole on it and sealed air tight with a sole tape. After sealing, 1-MCP was volatilized by addition of $30 \mathrm{ml}$ distilled water into the 1-MCP containing beaker using a syringe connected to a sizeable plastic pipe through the $1 \mathrm{~cm}$ diameter hole on the glass tank covering glass sheet. The hole was immediately closed with a stick staff. After $24 \mathrm{~h}$ of incubation, the closing glass sheet was removed, the Petri-dishes were closed, and the glass tank was kept open until the end of the germination experiment 
period. For $\mathrm{GA}_{3}$ containing treatments $\left(\mathrm{GA}_{3}, \mathrm{GA}_{3}+\right.$ ethylene, $\left.\mathrm{GA}_{3}+1-\mathrm{MCP}\right)$, seeds were treated with $\mathrm{GA}_{3}$ solution before being divided into sets of 100 seeds each. $\mathrm{GA}_{3}$ solution was prepared by diluting $6.7 \mathrm{mg} \mathrm{GA}_{3}$ (Sigma Aldrich, Johannesburg, South Africa) in 100 $\mathrm{ml} 48 \%$ ethanol ( $50 \mathrm{ml} 96 \%$ ethanol $+50 \mathrm{ml}$ distilled water) and the volume was adjusted to one litre by distilled water. Three millilitres of $\mathrm{GA}_{3}$ solution was sprayed to $100 \mathrm{~g}$ seeds. The seeds were left to air dry for $1 \mathrm{~h}$ at room temperature and then divided into sets of 100 seeds each. In the $\mathrm{GA}_{3}$ + ethylene treatment, seeds were treated with $\mathrm{GA}_{3}$ before being incubated in the ethylene containing atmosphere as explained for ethylene containing treatments. Again, in the $\mathrm{GA}_{3}+1-\mathrm{MCP}$ treatment, seeds were incubated in the 1-MCP containing atmosphere after treatment with $\mathrm{GA}_{3}$ solution. In the B-nine containing treatments (B-nine, ethylene $+\mathrm{B}$-nine, 1-MCP $+\mathrm{B}$-nine), filter papers in the Petri-dishes were moistened with $5 \mathrm{ml} \mathrm{B-nine} \mathrm{solution.} \mathrm{B-nine} \mathrm{solution} \mathrm{was} \mathrm{prepared} \mathrm{by} \mathrm{dissolving} 10 \mathrm{~g}$ B-nine powder (Uniroyal Chemical (Pvt) Ltd, USA) in one litre distilled water. In ethylene $+\mathrm{B}$-nine treatment, seeds were incubated in the ethylene containing atmosphere as explained for ethylene containing treatments and in the B-nine + 1-MCP treatment, seeds were incubated in the 1-MCP containing atmosphere as explained for 1-MCP containing treatments. The control seeds were also germinated on two layers Whatman No. 1 filter papers moistened with $5 \mathrm{ml}$ distilled water in $9 \mathrm{~cm}$ diameter Petri-dishes.

\section{Measurement of percent germination and rootlet growth}

Germinated seeds were removed and counted after 24, 48 and $72 \mathrm{~h}$ of incubation, respectively. Germination percentages were calculated as averages of germinated seeds from three replicates of each treatment. The other set of three replicates per treatment was used to assess rootlets length. At each evaluation interval, the lengths of the primary rootlets were measured on five randomly selected germinated seeds per replicate per treatment. The average rootlets length per treatment was calculated.

\section{Determination of the respiration rate}

\section{Treatments and the germination conditions}

The respiration rate of the germinating 'Puma' barley seeds was assessed on seeds treated with ethylene, $\mathrm{GA}_{3}, 1-\mathrm{MCP}, \mathrm{GA}_{3}+$ ethylene, $\mathrm{GA}_{3}+1-\mathrm{MCP}, \mathrm{B}$-nine, ethylene + B-nine, 1-MCP + B-nine and, the control. In all treatments, 3 replicates of $9 \mathrm{~g}$ seeds each were used. Each set of $9 \mathrm{~g}$ seeds (replicate) was incubated on two layers of Whatman No. 1 filter papers wetted with $8 \mathrm{ml}$ distilled water (except for B-nine containing treatments) in a $250 \mathrm{ml}$ air-tightly closed container placed in a germination chamber. The germination chamber was set at $20+1{ }^{\circ} \mathrm{C}$ and continuous darkness (except during evaluations). For ethylene containing treatments, $25 \mu$ l ethylene was injected in each tightly closed $250 \mathrm{ml}$ container using a syringe. For 1-MCP containing treatments, $100 \mu 11$-MCP gas was injected in each tightly closed $250 \mathrm{ml}$ container using a syringe. For $\mathrm{GA}_{3}$ containing treatments, $100 \mathrm{~g}$ seeds were sprayed with $3 \mathrm{ml} \mathrm{GA}_{3}$ solution and then divided into sets of $9 \mathrm{~g}$ 
each. In the B-nine containing treatments, filter papers were wetted with $8 \mathrm{ml}$ $\mathrm{B}$-nine solution. Preparation of B-nine and $\mathrm{GA}_{3}$ solutions was done following the procedures described under germination test (above). The control seeds were germinated on two layers Whatman No. 1 filter papers wetted with $8 \mathrm{ml}$ distilled water.

\section{Measurement of the respiration rate}

Respiration was measured as the amount of carbon dioxide evolved. Carbon dioxide was measured using F-950- three gas analyser (CID Bio-Science, Inc., $1554 \mathrm{NE} 3^{\text {rd }}$ Ave, Camas, WA 98607, USA). Respiration was measured at 24, 48 and $72 \mathrm{~h}$ of incubation, respectively. After the first $24 \mathrm{~h}$, the sample containers were removed from the germination chamber, air-tightly closed containers opened and blown with fresh air to flash out gases. The sample containers were then air-tightly closed and left to stand for $30 \mathrm{~min}$ before measuring carbon dioxide evolved during this period. After carbon dioxide measurement, seeds were taken out, blotted with a paper towel and weighed. The average weight of all treatments by replicates per evaluation period was used in calculating the respiration rate. After $24 \mathrm{~h}$ evaluation, the sample containers were closed, but, not airtightly. The respiration rate was calculated using the formula:

$$
R=[(c-r) \div 4] / g \times 2
$$

where $R$ is the respiration rate, $c$ is the carbon dioxide evolved over a period of $30 \mathrm{~min}$ in $\mu l$ per litre, $r$ is the carbon dioxide level of the experimental environment, 4 is a factor for converting one litre to the volume of the sample container $(250 \mathrm{ml}=1 / 4$ of a litre $)$, $g$ is the seed weight per replicate per evaluation time in grams and 2 is a factor for converting $30 \mathrm{~min}$ to one hour.

\section{Experimental design and data analysis}

Data for both experiments was analysed as factorial design with treatment and incubation period as factors. The data was applied to analysis of variance (ANOVA) using General Linear Models (GLM) in the Statistical Analysis System (SAS) computer programme (SAS Enterprise Guide 4.0; SAS Institute, 2006, Cary, NC 27513, USA). Means were separated using least squares difference (LSD) at 5\% level of significance. Graphs were drawn using Microsoft Office Excel 2007 (Microsoft Corporation, One Microsoft way, Redmond, WA 98052-7329, USA) computer programme.

\section{Results}

\section{Germination curves}

The germination curves for 'Puma' barley seeds treated with $\mathrm{GA}_{3}$, ethylene, 1-MCP, $\mathrm{GA}_{3}+1-\mathrm{MCP}, \mathrm{GA}_{3}+$ ethylene, B-nine, 1-MCP + B-nine, B-nine + ethylene and the con- 
trol are shown in Figure $\mathrm{S} 1 *$. The control, ethylene, $\mathrm{GA}_{3}, \mathrm{GA}_{3}+1-\mathrm{MCP}$ and $\mathrm{GA}_{3}+$ ethylene treated seeds had few seeds that germinated after $24 \mathrm{~h}$, the highest number of seeds that germinated after $48 \mathrm{~h}$ and again few seeds that germinated after $72 \mathrm{~h}$. Besides, $\mathrm{GA}_{3}+1-\mathrm{MCP}$ treated seeds had more seeds that germinated after $24 \mathrm{~h}$ compared to the control, ethylene, $\mathrm{GA}_{3}$ and $\mathrm{GA}_{3}+$ ethylene, respectively. Therefore, $\mathrm{GA}_{3}+1-\mathrm{MCP}$ treatment had lower number of seeds that germinated after $48 \mathrm{~h}$ compared to the control, ethylene, $\mathrm{GA}_{3}$ and $\mathrm{GA}_{3}+$ ethylene treatments, respectively. Ethylene, $\mathrm{GA}_{3}$ and $\mathrm{GA}_{3}+$ ethylene treatments had fewer seeds that germinated after $24 \mathrm{~h}$ and more seeds that germinated after $48 \mathrm{~h}$ compared to the control treatment. This shows that although ethylene, $\mathrm{GA}_{3}$, $\mathrm{GA}_{3}+1-\mathrm{MCP}$ and $\mathrm{GA}_{3}$ + ethylene treatments had similar triangular like shaped curves, the curves varies with treatments. 1-MCP treatment had more seeds that germinated after $24 \mathrm{~h}$, fewer seeds that germinated after $48 \mathrm{~h}$, and far few seeds that germinated after $72 \mathrm{~h}$. In B-nine containing treatments, no seed germinated after $24 \mathrm{~h}$, less than $20 \%$ of the seeds germinated after $48 \mathrm{~h}$ and less than $30 \%$ germination after $72 \mathrm{~h}$. Generally, germination increased with incubation time for the B-nine containing treatments.

\section{Cumulated percent germination}

The effects of $\mathrm{GA}_{3}$, ethylene, 1-MCP, $\mathrm{GA}_{3}+1-\mathrm{MCP}, \mathrm{GA}_{3}+$ ethylene, B-nine, 1-MCP $+\mathrm{B}$-nine, ethylene $+\mathrm{B}$-nine and the control on cumulated percent germination of 'Puma' barley seeds after 24, 48 and $72 \mathrm{~h}$ of incubation are shown on Table 1.

There was a significant interaction between incubation time and treatments on cumulated percent germination of 'Puma' barley seeds, $\mathrm{P}=0.000$. Moreover, there was a significant percent germination differences between treatments after $24(\mathrm{P}=0.000), 48$ $(\mathrm{P}=0.000)$ and $72 \mathrm{~h}(\mathrm{P}=0.000)$, respectively. Ethylene, $\mathrm{GA}_{3}$ and $\mathrm{GA}_{3}+$ ethylene treated seeds had significantly lower percent germination (5, 24 and $8 \%$, respectively) compared to the control (31\%) after $24 \mathrm{~h}$. 1-MCP and $\mathrm{GA}_{3}+1-\mathrm{MCP}$ treated seeds had significantly higher percent germination (61 and 38\%, respectively) compared to the control after $24 \mathrm{~h}$. Again, 1-MCP treated seeds had significantly higher percent germination $(61 \%)$ after $24 \mathrm{~h}$ compared to $\mathrm{GA}_{3}+1-\mathrm{MCP}(38 \%), \mathrm{GA}_{3}(24 \%)$ and ethylene $(5 \%)$ treated seeds, respectively. $\mathrm{GA}_{3}$ treated seeds had significantly higher percent germination (24\%) compared to ethylene treated seeds $(5 \%)$ after $24 \mathrm{~h}$. There was no germination recorded for all the B-nine containing treatments after $24 \mathrm{~h}$. There were no significant cumulated percent germination differences between treatments for the control, ethylene, GA $3,1-\mathrm{MCP}$, $\mathrm{GA}_{3}+1-\mathrm{MCP}$ and $\mathrm{GA}_{3}+$ ethylene treated seeds after 48 and $72 \mathrm{~h}$, respectively. The germination percentages for the control, ethylene, $\mathrm{GA}_{3}, 1-\mathrm{MCP}, \mathrm{GA}_{3}+1-\mathrm{MCP}, \mathrm{GA}_{3}+$ ethylene treated seeds were 95.3, 88.7, 93.3, 94.3, 98.0 and $98.7 \%$, respectively, after $48 \mathrm{~h}$ and $96.3,97.0,95.0,96.3,99.0$ and $99.3 \%$, respectively, after $72 \mathrm{~h}$. The germination percentages for the B-nine containing treatments were significantly low compared to non-B-nine containing treatments after 48 and $72 \mathrm{~h}$, respectively. The germination percentages of B-nine, ethylene + B-nine, B-nine + 1-MCP treated seeds were 10.3, 16.3 and 16.3\%,

*Further details about the Electronic Supplementary Material (ESM) can be found at the end of the article. 
Table 1. The effect of $\mathrm{GA}_{3}$, ethylene, 1-MCP, $\mathrm{GA}_{3}+1-\mathrm{MCP}, \mathrm{GA}_{3}+$ ethylene, B-nine, 1-MCP+B-nine, ethylene $+\mathrm{B}$-nine and the control treatments, respectively, on cumulated percent germination of 'Puma' barley seeds incubated for $72 \mathrm{~h}$ from soaking and evaluated after 24,48 and $72 \mathrm{~h}$, respectively

\begin{tabular}{|c|c|c|c|}
\hline \multirow{2}{*}{ Treatment } & \multicolumn{3}{|c|}{$\%$ Germination } \\
\hline & $24 \mathrm{hrs}$ & $48 \mathrm{hrs}$ & $72 \mathrm{hrs}$ \\
\hline Control & $31.0^{\mathrm{b}}$ & $95.3^{\mathrm{a}}$ & $96.3^{\mathrm{a}}$ \\
\hline Ethylene & $5.0^{\mathrm{d}}$ & $88.7^{\mathrm{a}}$ & $97.0^{\mathrm{a}}$ \\
\hline 1-MCP & $61.0^{\mathrm{a}}$ & $93.3^{\mathrm{a}}$ & $95.0^{\mathrm{a}}$ \\
\hline GA & $23.0^{\mathrm{bc}}$ & $94.3^{\mathrm{a}}$ & $96.3^{\mathrm{a}}$ \\
\hline B-nine & $0.0^{\mathrm{d}}$ & $10.3^{b}$ & $31.3^{\mathrm{b}}$ \\
\hline $\mathrm{GA}+$ Ethylene & $8.3^{\mathrm{cd}}$ & $98.7^{\mathrm{a}}$ & $99.3^{\mathrm{a}}$ \\
\hline $\mathrm{GA}+1-\mathrm{MCP}$ & $38.3^{\mathrm{b}}$ & $98.0^{\mathrm{a}}$ & $99.0^{\mathrm{a}}$ \\
\hline Ethylene + B-nine & $0.0^{\mathrm{d}}$ & $16.3^{\mathrm{b}}$ & $40.0^{\mathrm{b}}$ \\
\hline 1-MCP + B-nine & $0.0^{\mathrm{d}}$ & $16.3^{\mathrm{b}}$ & $42.0^{\mathrm{b}}$ \\
\hline$P$ values & 0.000 & 0.000 & 0.000 \\
\hline Treatment & & & 0.000 \\
\hline Incubation period & & & 0.000 \\
\hline Treatment $\times$ incubation period & & & 0.000 \\
\hline
\end{tabular}

Means with similar superscript within a column are not significantly different at $5 \%$ level.

respectively, after $48 \mathrm{~h}$ and 31.3, 40.0 and $42.0 \%$, respectively, after $72 \mathrm{~h}$. The germination suppression effect of B-nine was also shown on Figure S2. B-nine containing treatments suppressed germination, but, $\mathrm{GA}_{3}$ treated and the control seeds germinated well after $72 \mathrm{~h}$ of incubation.

\section{Rootlets length}

The effect of $\mathrm{GA}_{3}$, ethylene, 1-MCP, $\mathrm{GA}_{3}+1-\mathrm{MCP}, \mathrm{GA}_{3}+$ ethylene, B-nine, 1-MCP + B-nine, ethylene + B-nine and the control on rootlets length of germinating 'Puma' barley seeds after 24, 48 and $72 \mathrm{~h}$ of incubation are shown on Table 2.

There was a significant interaction between incubation time and treatments on rootlets length of the germinating 'Puma' barley seeds, $\mathrm{P}=0.000$. Moreover, there was a significant rootlets length differences between treatments after $24(\mathrm{P}=0.000), 48(\mathrm{P}=0.000)$ and $72 \mathrm{~h}(\mathrm{P}=0.000)$, respectively. There were no significant rootlets length differences between the control $(2.9 \mathrm{~mm}), \mathrm{GA}_{3}(3.2 \mathrm{~mm})$ and $\mathrm{GA}_{3}+1-\mathrm{MCP}(3.6 \mathrm{~mm})$ treated seeds after $24 \mathrm{~h}$. The rootlets of 1-MCP treated seeds were significantly longer $(4.2 \mathrm{~mm})$ compared to the control seeds $(2.9 \mathrm{~mm})$ after $24 \mathrm{~h}$. There were no significant rootlets length differences between 1-MCP $(4.2 \mathrm{~mm})$ and $\mathrm{GA}_{3}+1-\mathrm{MCP}(3.6 \mathrm{~mm})$ treated seeds after $24 \mathrm{~h}$. The rootlets of ethylene and $\mathrm{GA}_{3}+$ ethylene treated seeds were significantly short (1.1 and $1.3 \mathrm{~mm}$, respectively) compared to the control, 1-MCP, $\mathrm{GA}_{3}$ and $\mathrm{GA}_{3}+1-\mathrm{MCP}$ 
Table 2. The effect of $\mathrm{GA}_{3}$, ethylene, 1-MCP, $\mathrm{GA}_{3}+1-\mathrm{MCP}, \mathrm{GA}_{3}+$ ethylene, B-nine, 1-MCP+B-nine, ethylene $+\mathrm{B}$-nine and the control treatments on rootlets length of germinating 'Puma' barley seeds after 24, 48 and $72 \mathrm{~h}$ of incubation, respectively

\begin{tabular}{|c|c|c|c|}
\hline \multirow{2}{*}{ Treatment } & \multicolumn{3}{|c|}{ Rootlet length (mm) } \\
\hline & $24 \mathrm{hrs}$ & $48 \mathrm{hrs}$ & $72 \mathrm{hrs}$ \\
\hline Control & $2.9^{\mathrm{b}}$ & $12.4^{b}$ & $22.5^{\mathrm{a}}$ \\
\hline Ethylene & $1.1^{\mathrm{c}}$ & $8.5^{\mathrm{c}}$ & $16.2^{\mathrm{b}}$ \\
\hline 1-MCP & $4.3^{\mathrm{a}}$ & $13.3^{\mathrm{ab}}$ & $23.6^{\mathrm{a}}$ \\
\hline GA & $3.2^{\mathrm{b}}$ & $11.9^{b}$ & $21.4^{\mathrm{a}}$ \\
\hline B-nine & $0.0^{\mathrm{d}}$ & $3.0^{\mathrm{d}}$ & $5.1^{\mathrm{c}}$ \\
\hline GA + Ethylene & $1.3^{\mathrm{c}}$ & $9.5^{\mathrm{c}}$ & $20.5^{b}$ \\
\hline $\mathrm{GA}+1-\mathrm{MCP}$ & $3.6^{\mathrm{ab}}$ & $14.6^{\mathrm{a}}$ & $20.7^{\mathrm{b}}$ \\
\hline Ethylene + B-nine & $0.0^{\mathrm{d}}$ & $1.5^{\mathrm{d}}$ & $3.1^{\mathrm{c}}$ \\
\hline 1-MCP + B-nine & $0.0^{\mathrm{d}}$ & $2.3^{\mathrm{d}}$ & $4.0^{\mathrm{c}}$ \\
\hline$P$ values & 0.000 & 0.000 & 0.000 \\
\hline Treatment & & & 0.000 \\
\hline Incubation period & & & 0.000 \\
\hline Time $\times$ Incubation period & & & 0.000 \\
\hline
\end{tabular}

Means with similar superscript within a column are not significantly different at $5 \%$ level.

treated seeds after $24 \mathrm{~h}$. There were no rootlets length recorded for B-nine containing treatments after $24 \mathrm{~h}$. There were no significant rootlets length differences for the control (12.4 mm), 1-MCP $(13.3 \mathrm{~mm})$ and $\mathrm{GA}_{3}(11.9 \mathrm{~mm})$ treated seeds after $48 \mathrm{~h} . \mathrm{GA}_{3}+1-\mathrm{MCP}$ treated seeds had significantly longer rootlets $(14.6 \mathrm{~mm})$ compared to the control $(12.4$ $\mathrm{mm})$. However, the rootlets length of $\mathrm{GA}_{3}+1-\mathrm{MCP}$ and 1-MCP treated seeds were not significantly different after $48 \mathrm{~h}$. The rootlets for ethylene and $\mathrm{GA}_{3}+$ ethylene treated seeds were significantly short ( 8.5 and $9.5 \mathrm{~mm}$, respectively) compared to the control, 1-MCP, $\mathrm{GA}_{3}$ and $\mathrm{GA}_{3}+1-\mathrm{MCP}$ treated seeds, respectively, after $48 \mathrm{~h}$. However, the rootlets length of ethylene and $\mathrm{GA}_{3}+$ ethylene treated seeds were not significantly different after $48 \mathrm{~h}$. The rootlets length for B-nine, ethylene + B-nine and 1-MCP + B-nine treated seeds were significantly short $(3.0,2.3$ and $1.5 \mathrm{~mm}$, respectively) compared to the control, 1-MCP, $\mathrm{GA}_{3}, \mathrm{GA}_{3}+1-\mathrm{MCP}$, ethylene and $\mathrm{GA}_{3}+$ ethylene treated seeds, respectively, after $48 \mathrm{~h}$. However, the rootlets length for B-nine, ethylene + B-nine and 1-MCP + B-nine were not significantly different after $48 \mathrm{~h}$. After $72 \mathrm{~h}$, the rootlets length of the control $(22.5 \mathrm{~mm}), \mathrm{GA}_{3}(21.4 \mathrm{~mm})$ and 1-MCP $(23.6 \mathrm{~mm})$ treated seeds were not significantly different. The rootlets for ethylene, $\mathrm{GA}_{3}+$ ethylene and $\mathrm{GA}_{3}+1-\mathrm{MCP}$ treated seeds were significantly short $\left(16.2,20.5\right.$ and $20.7 \mathrm{~mm}$, respectively) compared to the control, $\mathrm{GA}_{3}$ and 1-MCP treated seeds. The rootlets of B-nine, ethylene $+\mathrm{B}-$ nine and 1-MCP $+\mathrm{B}-$ nine treated seeds were significantly short $(5.1,4.0$ and $3.1 \mathrm{~mm}$, respectively) compared to the control, 1-MCP, $\mathrm{GA}_{3}$, ethylene, $\mathrm{GA}_{3}$ + ethylene and $\mathrm{GA}_{3}+1-\mathrm{MCP}$ treated seeds, respec- 
tively. However, the rootlets length of B-nine, ethylene $+\mathrm{B}-$ nine and 1-MCP $+\mathrm{B}$-nine treated seeds were not significantly different.

The effect of ethylene on rootlets growth of the germinating 'Puma' barley seeds was further emphasised in Figure S3. The rootlets lengths of ethylene treated 'Puma' seeds were shorter than 1-MCP treated and the control seeds after 48 and $72 \mathrm{~h}$ of incubation, respectively.

\section{Respiration}

The effects of $\mathrm{GA}_{3}$, ethylene, 1-MCP, $\mathrm{GA}_{3}+1-\mathrm{MCP}, \mathrm{GA}_{3}$ + ethylene, B-nine, 1-MCP + B-nine, ethylene + B-nine and the control treatments on the rate of respiration of the germinating 'Puma' barley seeds are shown on Table S1. There was no significant interaction between incubation time and treatment on the respiration rate of the germinating 'Puma' barley seeds, $\mathrm{P}=0.079$. However, there was a significant respiration rate differences between treatments, $\mathrm{P}=0.000$. The respiration rates for the seeds treated with ethylene $(107.7 \mu \mathrm{l} / \mathrm{g} / \mathrm{hr}), 1-\mathrm{MCP}(110.5 \mu \mathrm{l} / \mathrm{g} / \mathrm{hr}), \mathrm{GA}_{3}(111.2 \mu \mathrm{l} / \mathrm{g} / \mathrm{hr}), \mathrm{GA}_{3}+$ ethylene $(123.5 \mu \mathrm{l} / \mathrm{g} / \mathrm{hr}), \mathrm{GA}_{3}+1-\mathrm{MCP}(121.1 \mu \mathrm{l} / \mathrm{g} / \mathrm{hr})$ and the control $(104.2 \mu \mathrm{l} / \mathrm{g} / \mathrm{hr})$ were not significantly different. However, the respiration rates of B-nine, ethylene $+\mathrm{B}$-nine and 1-MCP + B-nine treated seeds were significantly low $(66.8,70.4$ and $67.3 \mu \mathrm{l} / \mathrm{g} / \mathrm{hr}$, respectively) compared to non-B-nine containing treatments. Again, there were significant respiration rate differences between incubation times, $\mathrm{P}=0.000$. The respiration rate of the germinating 'Puma' barley seeds was significantly low $(68.9 \mu \mathrm{l} / \mathrm{g} / \mathrm{hr})$ after $24 \mathrm{~h}$ compared to $48(112.2 \mu \mathrm{l} / \mathrm{g} / \mathrm{hr})$ and $72 \mathrm{~h}(113.1 \mu \mathrm{l} / \mathrm{g} / \mathrm{hr})$, respectively. However, there was no significant respiration rate difference between 48 and $72 \mathrm{~h}$ of incubation.

\section{Discussion}

During germination, the barley seed produces GA (Palmer 2018) and ethylene (Locke et al. 2000; Hartman et al. 2011) which regulates embryo growth and enzyme synthesis. Since both ethylene and GA are produced by the germinating barley seed and their presence either in or around the seed affects germination, the separate roles of these hormones on barley seed germination are not clear. This study, therefore, used hormone inhibitors to study the effects of one hormone in the absence of the other. 1-MCP was used to inhibit ethylene action and daminozide (B-nine) to inhibit GA synthesis. 1-MCP inhibits ethylene action by competing with ethylene for membrane bound receptors (Taiz and Zeiger 2010) and B-nine inhibits GA synthesis by inhibiting 2-oxoglutrate-dependent dioxygenase, an important enzyme in the synthesis of bioactive GAs (Rademacher 2000). Comparisons were made on germination curves, percent germination, rootlets length and the respiration rates of 'Puma' barley seeds treated with $\mathrm{GA}_{3}$, ethylene, 1-MCP, $\mathrm{GA}_{3}+$ 1-MCP, $\mathrm{GA}_{3}$ + ethylene, B-nine, 1-MCP + B-nine, ethylene + B-nine and the control.

The germination curves showed that, both ethylene and GA regulates germination of 'Puma' barley seeds. Inhibiting ethylene perception with 1-MCP as well as inhibiting GA biosynthesis with B-nine changed the shape of the germination curve of 'Puma' barley 
(the control). The germination curve of 'Puma' barley seeds showed that few seeds germinate after $24 \mathrm{~h}$, the highest number of seeds after $48 \mathrm{~h}$ and again few seeds after $72 \mathrm{~h}$. Conversely, seeds treated with 1-MCP had large number of seeds that germinated after 24 $\mathrm{h}$, few seeds after $48 \mathrm{~h}$, and far fewer seeds after $72 \mathrm{~h}$. The B-nine treated seeds showed no germination after $24 \mathrm{~h}$, less than $20 \%$ germination after $48 \mathrm{~h}$ and less than $30 \%$ germination after $72 \mathrm{~h}$. $\mathrm{GA}_{3}$, ethylene and $\mathrm{GA}_{3}$ + ethylene treated seeds, though with slight variations, have normal germination curve shapes (where few seeds germinate after $24 \mathrm{~h}$, large number of seeds after $48 \mathrm{~h}$, and again, few seeds after $72 \mathrm{~h}$ ).

The germination curves also suggested that ethylene is the dominant hormone that determines the rate of germination of 'Puma' barley seed. Considering that ethylene is synthesised by germinating barley seeds (Locke et al. 2000; Hartman et al. 2011), the curves showed that supplementing ethylene synthesised by seeds (control) by exogenous ethylene treatment further reduces the number of seeds that germinates after $24 \mathrm{~h}$ and increases the number of seeds that germinates after $48 \mathrm{~h}$. Moreover, inhibiting ethylene perception increased the number of seeds that germinated after $24 \mathrm{~h}$. It could be concluded that ethylene treatment delays germination of 'Puma' barley and inhibiting its perception hastens germination.

The germination curves also suggested that $\mathrm{GA}_{3}$ treatment enhances the negative effect of ethylene on the rate of 'Puma' barley seed germination. Compared to the control, $\mathrm{GA}_{3}$ in $\mathrm{GA}_{3}$ + ethylene combination treatment did not increase the number of seeds that germinated after $24 \mathrm{~h}$. Again, $\mathrm{GA}_{3}$ in $\mathrm{GA}_{3}+1-\mathrm{MCP}$ combination treatment reduced the germination stimulation effect of 1-MCP after $24 \mathrm{~h}$. Moreover, though less than ethylene, increasing endogenous GA (control) with exogenous $\mathrm{GA}_{3}$ treatment decreased the number of seeds that germinated after $24 \mathrm{~h}$ and increased the number of seeds that germinated after $48 \mathrm{~h}$ (a trend that was observed with ethylene treatment).

Although ethylene delayed germination of 'Puma' barley seeds, it had no effect on ultimate cumulated percent germination. Germination is deemed to be complete when the seed's embryonic axis (radical or plumale) have protruded out of the structures surrounding the embryo (Bewley and Black 1994; Bewley 2001). In the current study, seeds were considered to have germinated after radical protrusion from both testa and coleorhiza. Although ethylene treated seeds had significantly low percent germination compared to the control and 1-MCP treated seeds after $24 \mathrm{~h}$, the cumulated percent germination of ethylene treated seeds was not significantly different from both the control and 1-MCP treated seeds after 48 and $72 \mathrm{~h}$, respectively. However, in barley germination technologies such as malting, a delay in germination may cause poor malt modification (Briggs 1998). Again, delayed germination may mean delayed enzyme development and reserve mobilisation hence delayed seedling development.

The cumulated percent germination results also showed that GA is the dominant hormone that regulates germination in 'Puma' barley seeds. All the B-nine containing treatments had significantly lower percent germination compared to all non-B-nine containing treatments. Again, although ethylene was reported to restore germination of GA deficient mutant gal-3 in Arabidopsis (Corbineau et al. 2014), ethylene in B-nine + ethylene treatment did not rescue B-nine induced germination inhibition in 'Puma' barley seeds. This 
suggests that GA synthesis is important for 'Puma' seed germination. Matilla and MatillaVázquez (2008) also reported that GA and ethylene work together, but, GA is qualitatively and quantitatively more important. However, $\mathrm{GA}_{3}$ treated seeds had significantly lower percent germination after $24 \mathrm{~h}$, but, no significant cumulated percent germination differences compared to the control after 48 and $72 \mathrm{~h}$, respectively. This may suggest that after-ripened 'Puma' barley seeds produce enough GA to promote germination and hence, increasing endogenous GA delay germination, but, has no effect on ultimate percent germination of 'Puma' barley seeds. Very low $\mathrm{GA}_{3}$ rates $(0.2-0.25 \mathrm{ppm})$ are generally used to treat barley grain during malting (Briggs 1998; Palmer 2018). Again, optimum levels of $\mathrm{GA}_{3}$ are generally known to promote rapid seed germination (Briggs 1998).

Analysis of rootlets length showed that ethylene suppresses rootlets elongation. Ethylene is generally known to inhibit and GA to promote rootlet elongation (Taiz and Zeiger 2010). In the present work, inhibiting ethylene action by 1-MCP, exogenous application of GA and exogenous application of a combination of GA and 1-MCP had significantly longer rootlets compared to ethylene treatment after 24,48 and $72 \mathrm{~h}$, respectively. However, there were no significant rootlets length differences between ethylene and $\mathrm{GA}_{3}+$ ethylene treatment after 24, 48 and $72 \mathrm{~h}$, respectively. This suggests that GA treatment cannot rescue germinating 'Puma' barley seeds from ethylene induced suppression of rootlets growth.

Rootlets elongation results also indicated that GA synthesis is important for rootlet growth. The rootlets lengths of B-nine containing treatments were significantly short compared to the control, 1-MCP, $\mathrm{GA}_{3}, \mathrm{GA}_{3}+1-\mathrm{MCP}$, ethylene and $\mathrm{GA}_{3}+$ ethylene, respectively, after 48 and $72 \mathrm{~h}$. The rootlets length of B-nine + ethylene treated seeds, though not significantly short, were slightly shorter compared to other B-nine containing treatments after 48 and $72 \mathrm{~h}$, respectively. These results suggest that the rootlets elongation suppression effect of ethylene is less effective if GA synthesis is not inhibited. Again, the results suggest that ethylene and B-nine may have additive effects on suppression of rootlets elongation.

Analysis of the rate of respiration showed that the respiration rate of the germinating 'Puma' barley seeds increased with incubation time and plateaus after $48 \mathrm{~h}$. However, the respiration rate remains high after $72 \mathrm{~h}$. Ethylene had no significant effect on the respiration rate of germinating 'Puma' barley seeds. Both, ethylene treated and 1-MCP treated seeds had no significant respiration rates differences compared to the control. However, the results suggested that GA synthesis is important for respiration of the germinating 'Puma' barley seeds. Inhibiting GA synthesis significantly decreased the respiration rate of the germinating 'Puma' barley seed. However, the respiration rate of $\mathrm{GA}_{3}$ treated seeds was not significantly different from the control. This further suggest that after-ripened 'Puma' barley seeds produce enough GA to promote normal respiration during germination and, hence, increasing GA level has no effect on respiration, but, low levels of GA due to inhibition of biosynthesis reduce respiration. Germinating B-nine treated seeds in the presence of ethylene did not rescue 'Puma' barley seeds from B-nine induced reduction of the respiration rate. Generally, respiration rate correlates with the rate of metabolism (Bewley and Black 1994) and normal seed metabolism is important for seed germi- 
nation. These results therefore suggest that endogenous GA synthesis is important for 'Puma' barley seed metabolism during germination.

\section{Conclusion}

The results suggested that GA is the dominant hormone that regulates germination of 'Puma' barley seeds. However, ethylene regulates the germination rate of 'Puma' barley seeds through suppression of rootlets elongation. Besides, the rootlet growth suppression effect of ethylene could not inhibit germination of 'Puma' barley seeds if GA synthesis is active. This could be partly because GA is important for the respiration process. However, increasing $\mathrm{GA}$ level by exogenous $\mathrm{GA}_{3}$ treatment could also delay germination of 'Puma' barley seeds. However, this increased GA level induced delay in germination is less compared to that of ethylene treatment. It could be hypothesised that increased level of GA cause seed stress, hence, delayed germination. Since germination delaying was found to be the effect of ethylene treatment, future studies should investigate if the germination delaying effect of $\mathrm{GA}_{3}$ treatment is not a result of GA induced ethylene synthesis.

\section{Acknowledgements}

The author is grateful to SAB-Alrode malting for donating 'Puma' barley grain that was used in this study. The contribution of Prof. Charles Stephen Whitehead who assisted with experimental design and data interpretation is also highly appreciated.

\section{References}

Bewley, J.D., Black, M. 1994. Seeds: physiology of development and development (2 ${ }^{\text {nd }}$ edn). Plenum Press, New York.

Bewley, J.D. 2001. Seed germination and reserve mobilization. ENCYCLOPEDIA OF LIFE SCIENCES: Nature Publishing Group / www.els.net

Briggs, D.E. 1998. Malts and malting. Springer. USA.

Calvo, A.P., Nicolas, C., Lorenzo, O., Nicolas, G., Rodriguez, D. 2004a. Evidence for positive regulation by gibberellins and ethylene of ACC oxidase expression and activity during transition from dormancy to germination in Fagus sylvatica L. seeds. J. Plant Growth Regul. 23:44-53.

Corbineau, F., Qiong, O., Bailly, C., El-Maarouf-Bouteau, H. 2014. Ethylene, a key factor in the regulation of seed dormancy. Frontiers of Plant Science. 5:539.

Hartman, I., Sladarsky, V.U.P., Fiserova, H., Helanova, A., Sladarsky, V.U.P., Prokes, J., Sladarsky, V.U.P., Hartmann, J. 2011. Influencing malt quality by exogenous ethylene application performed in the course of post-harvest ripening of barley grain. Kvasny Prumysl (Czech Republic).

Kucera, B., Cohn, M.A., Leubner-Metzger, G. 2005. Plant hormone interactions during seed dormancy release and germination. Seed Sci. Res. 15:281-307.

Locke, J.M., Bryce, H.J., Morris, C.P. 2000. Contrasting effects of ethylene perception and biosynthesis inhibitors on germination and seedling growth of barley (Hordeum vulgare L.). J. Exp. Bot. 51:18431849.

Miransari, M., Smith, D.L. 2014. Plant hormones and seed germination. Journal of Environmental Botany 99:110-121.

Matilla, A.J., Matilla Vázquez, M.A. 2008. Involvement of ethylene in seed physiology. Plant Sci. 175:87-97. 
Palmer, G.H. 2018. Barley and malt. In: Stewart, G.H., Russel, I., Anstruther, A. (eds) Handbook of brewing. 3rd Edtion. CRC Press, Taylor \& Francis Group, Boca Raton. pp. 107-126.

Rademacher, W. 2000. Growth retardants: Effects on gibberellin biosynthesis and other metabolic pathways. Annu. Rev. Plant Biol. 51(1):501-531.

Taiz, L., Zeiger, E. 2010. Plant physiology (5th edn). Sinauer Associates Inc. Sunderland, Massachusetts.

\section{Electronic Supplementary Material (ESM)}

Electronic Supplementary Material (ESM) associated with this article can be found at the website of CRC at http://www.akademiai.com/content/120427/

Electronic Supplementary Table S1. The effect of $\mathrm{GA}_{3}$, ethylene, 1-MCP, $\mathrm{GA}_{3}+1-\mathrm{MCP}, \mathrm{GA}_{3}+$ ethylene, $\mathrm{B}-$ nine, 1-MCP $+\mathrm{B}$-nine, ethylene $+\mathrm{B}$-nine and the control treatments on the respiration rate of germinating 'Puma' barley seeds after 24, 48 and $72 \mathrm{~h}$ of incubation, respectively

Electronic Supplementary Figure S1. The germination curves of 'Puma' barley seeds treated with ethylene, $\mathrm{GA}_{3}, 1-\mathrm{MCP}, \mathrm{GA}_{3}+$ ethylene, $\mathrm{GA}_{3}+1-\mathrm{MCP}, \mathrm{B}-$ nine, B-nine + ethylene, 1-MCP+B-nine and the control, respectively, and evaluated at $24 \mathrm{~h}$ intervals over a period of $72 \mathrm{~h}$ from soaking. The markers how the number of seeds that germinated after 24,48 and $72 \mathrm{~h}$ of incubation, respectively

Electronic Supplementary Figure S2. B-nine, ethylene + B-nine and 1-MCP+B-nine treatments caused poor germination of 'Puma' barley seeds compared to $\mathrm{GA}_{3}$ and the control treatments after $72 \mathrm{~h}$ of incubation

Electronic Supplementary Figure S3. The rootlets lengths of ethylene treated 'Puma' seeds were shorter than $1-\mathrm{MCP}$ treated and the control seeds after both 48 and $72 \mathrm{~h}$ from soaking 